\title{
Axel Gänsslen, Michael Muller, Michael Nerlich (eds): Acetabular fractures: diagnosis, indications, treatment strategies
}

\section{Thieme Verlag, New York, Stuttgart, Delhi, Rio de Janeiro, 2017, 356 pp, 921 figs., 310,00 mm, Hardcover (GEB) + Video access (5), EUR (D) 249,99 EUR (A) 257,00 CHF 287,00, ISBN: 978-3-13- 241560-7}

\section{Pierre Kehr ${ }^{1}$}

Received: 6 May 2018 / Accepted: 20 May 2018 / Published online: 4 June 2018

(c) Springer-Verlag France SAS, part of Springer Nature 2018

True bible of the fractures of the acetabulum, this book is due to the collaboration of 21 authors specialized and considered in the diagnosis and the treatment of these fractures. It is divided into 25 chapters, since the recall of the surgical anatomy, the concepts biomechanical, the radiological diagnosis and classifications according to Böhler, Letournel and that of AO/OTA. After the approaches, the principal isolated types are then studied one after the others, with each time the same plan: anatomo-radiological characteristics, criteria, pathological mechanism, effect on the stability of the hip, biomechanics, indications therapeutic, technical and osteosynthesis. The fractures of two columns, those of the elderly, the child. Follow now; then peri-prosthetic complications and fractures.

This imposing work, very complete, is to be put in the professional library of any traumatologist, experienced and trainees.

\section{Compliance with ethical standards}

Conflict of interest The author declares that he has no competing interests. 